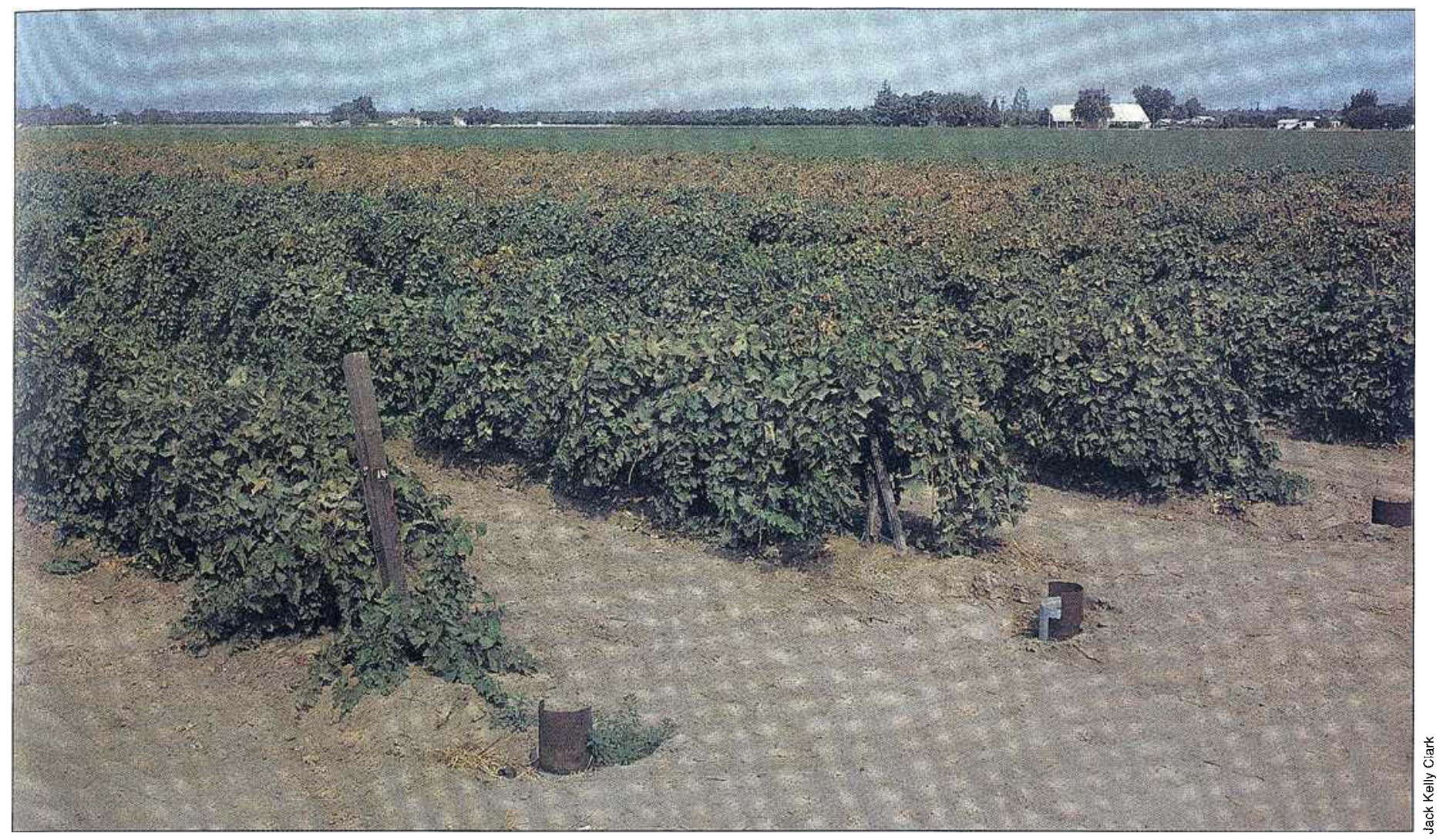

The Pacific spider mite (below) causes considerable damage to California vineyards, as can be seen at right in the photograph above. $\mathrm{Be}-$ cause the vines in the foreground above were inoculated earlier in the season with harmless levels of Willamette mites (bottom), they were left undamaged by the Pacific spider mites.
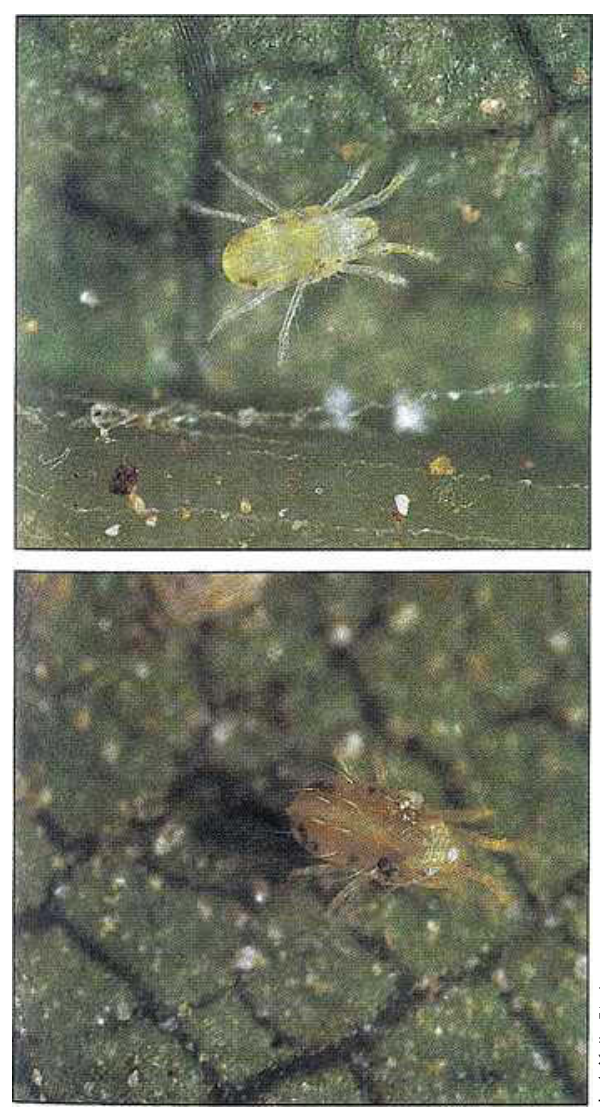

\title{
Vaccinating grapevines against spider mites
}

\author{
Richard Karban $\square$ Gregory English-Loeb $\square \quad$ Paul Verdegaal
}

\section{Central Valley grape growers can reduce damage from Pacific mites by inoculating infested vines with the less-damaging Willamette mites. Such "vaccinations" may become a useful technique for pest management.}

Traditionally, people have assumed that plants were the unresponsive victims of attacks by insects, mites, and pathogens. Evidence gathered over the past decade, however, indicates that plants change following such attacks. Attacked plants variously synthesizeand accumulate novel chemicals, activate enzyme systems, alter their rates of transpiration and photosynthesis, excrete plant hormones, and rearrange their essential metabolic constituents. In short, scientists have found that almost every important plant property they havethought to measure has changed under certain circumstances of attack.

Some of these plant changes make the injured plant less suitable as a host for subsequent attackers. Not all damage-induced plant changes reduce host suitability; many have no direct effect on herbivores, while others may increase the performance of insects and mites.

We have been looking at ways to let the plant changes induced by one pest species protect plants against a second, potentially more damaging, species. Plant pathologists have succeeded in similar attempts to protect plants against damaging viral, bacterial, and fungal strains. Commercial tomato growers over much of northern Europe routinely inoculateplants with a less-virulent strain of mosaic virus as a protection against more virulent, economically damaging strains.

Induced resistance does not provide plants the complete, long-lasting protection 
we expect from our own antigen-antibody vaccines. The plants' response also appears to be more general than analogous animal responses: for example, resistance in cotton is triggered by diverse forms of damage and is active against a wide variety of insects, mites, and diseases. While the mechanisms and nature of induced resistance are very different in plants than in vertebrates, similar "vaccination" techniques may be possible.

\section{Two spider mites}

Grapevines in the San Joaquin Valley are most often attacked by two spider mite species. Willamette mites (Eotetranychus willametti) are the less injurious of the two. At times they cause leaves to yellow, but they rarely build up to densities that can causeeconomic damage. Pacific spider mites (Tetranychus pacificus) can cause leaves to turn brown and abscise prematurely, and can reduce the sugar concentration in fruit. Pacific spider mites can also reduce vine growth and crop yields the year after infestation.

Many workers have noted a negative association between these two species in the Central Valley. Vines that have populations of Willamette mites, especially early in the season, tend not to develop damaging populations of Pacific spider mites. Vines with high Pacific spider mite populations tend not to have Willamette mites. Although we do not yet understand the mechanism of this negative association, we wondered whether by inoculating vines early in the season with the economically less damaging Willamette mites, we might be able to protect the vines from the more damaging $\mathrm{Pa}$ cific spider mites.

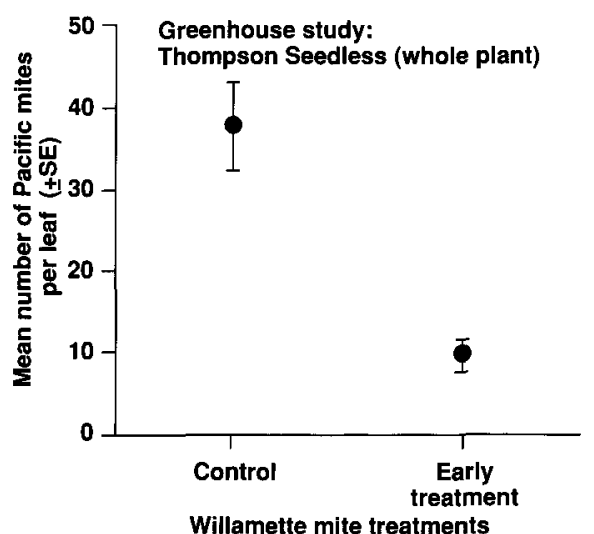

Fig. 1. Mean number of Pacific spider mites per leaf on potted Thompson Seedless vines that received an early release $(n=41)$ of Willamette mites $(696 \pm 237$ eggs on each plant) and control vines that did not $(n=43)$. Willamette mites were removed with Kelthane (controls were also treated) after 4 weeks of feeding and before release of Pacific spider mites. Pacific spider mites fed on the same leaves previously injured by Willamette mites.

\section{Experimental inoculations}

We experimentally inoculated vines with Willamette mites in the greenhouse, in smallscale field plots, and in commercial vineyards. In each experiment we established two treatments: vines on which we did release Willamette mites, and control vines on which we did not. We released Willamette mites either late in autumn just before leaf fall, early in spring just after bud break, or in late spring or early summer in some greenhouse experiments. The numbers of mites released ranged from 700 eggs and mobile mites $( \pm 200)$ per potted vine in the greenhouse, to 40 immature and adult mites per plant for 1-year-old vines in small plots, to 400 or 1,000 eggs and mobile mites per vine for older, established plants in a commercial vineyard.

We conducted the greenhouse and small plot experiments in Davis, and the largescale experiments in the Lodi area. Throughout each experiment, the number of Willamette mites on our release vines exceeded that on our controls, indicating that we were successful in establishing our treatments. In no case did Willamette mite populations reach the economic threshold of 30 mites per leaf established by Steve Welter and his colleagues.

Our first experiments involved Thompson Seedless vines in the greenhouse in their first year of life. Pacific spider mite populations peaked at lower levels on plants that had been exposed to Willamette mites than on controls (fig. 1). In this experiment, Pacific spider mites fed on the same leaves previously injured by Willamette mites.

We next tried a similar experiment with 1-year-old Chardonnay and Zinfandel vines in the field. Since the results for the two grape varieties did not differ, we analyzed them together. Each vine constituted a replicate, and treated and control vines were randomly interspersed throughout our field.

In this experiment, we released Willamette mites early in the season (June 17, just after bud break; $n=22$ ), later in the season (July 28, when Pacific spider mite populations were beginning to increase; $\mathbf{n}=$ $22)$, and at both times $(n=22)$. For vines that only received the early release, we assayed Pacific spider mites on new leaves produced by the plant after the Willamette mites had been removed (we removed the Willamette mites 4 weeks after release). For vines that received the late release, we assayed Pacific mites on the same leaves that had previously been damaged. Pacific spider mite density was greater on control vines than on any inoculated vines (fig. 2).

Finally, we conducted larger-scale inoculations in a commercial Zinfandel vineyard north of Lodi managed by Tony Racco. This vineyard had been the site of chronic Pacific mite problems for at least the previ- ous 4 years. Mr. Racco had relied on miticides for control, although they had come to require substantial expense and their control did not last long. Here, our sampling unit was a row of vines. Experimental rows either did or did not receive Willamette mites, and were separated from one another by a single buffer row.

Early in the 1988 season, Pacific spider mites were rare on all vines (fig. 3). As populations increased in June, we found more mites on control vines than on inoculated vines. Late in June, Mr. Racco treated the entire vineyard with propargite (Omite

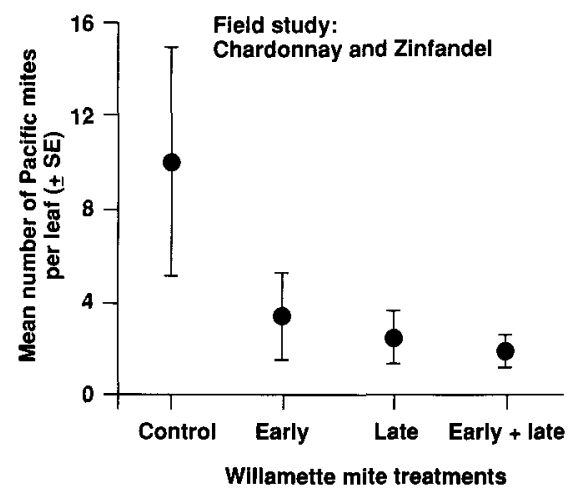

Fig. 2. Mean number of Pacific spider mites per leaf from Chardonnay and Zinfandel vines, as a function of exposure of vines to Willamette mites. "Control" vines were kept free of Willamette mites; "early Willamette" vines received Willamette mites on lower leaves only; "late Willamette" vines received Willamette mites on an upper isolated leaf at the same time as they received Pacific spider mites; "early and late Willamette" vines received Willamette mites on lower leaves and on the isolated upper leaf with Pacific spider mites. Each Willamette mite release included 40 large immatures or adults.

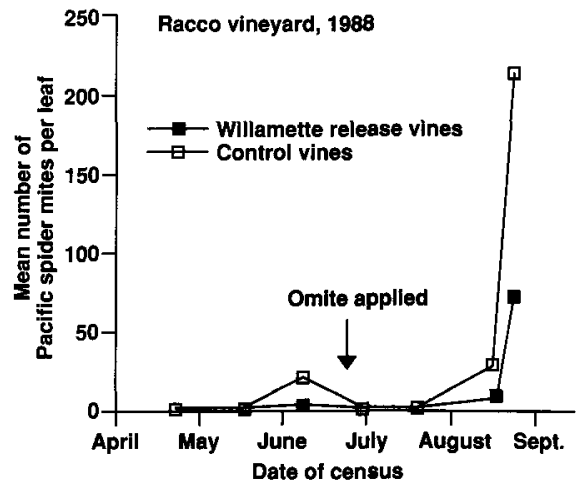

Fig. 3. Pacific spider mite populations on experimental Zinfandel vines throughout the 1988 growing season. Release vines $(n=10$ rows) received 1,050 \pm 226 Willamette mites each on November 3 , and control vines $(n=10$ rows) received no Willamette mites. 
WP). This effectively reduced mite populations on all vines, and we thought our experiment was over. However, as Pacific spider mite populations resurged later in the season, more mites were again found on controls than on vines where we had released Willamette mites (fig. 3). We censused these same vines the next year (1989) as well, and found no residual differences in Willamette mite or Pacific spider mite populations.

We repeated this experiment in 1989 in a different portion of the same vineyard. As in 1988, Pacific spider mite populations were much lower on plants that had been inoculated than on uninoculated controls (fig. 4). Mr. Racco again applied one treatment of propargite, this time in early July. After this application, mite populations remained low for the rest of the season.

Pacific spider mites only cause problems for grape growers when they reduce grape yields and sugar content. Similarly, our "vaccination" technique will be useful only if it leads to greater profits or lower production costs for harvested grapes. For wine grapes, sugar concentration often responds to mite damage. A small difference in sugar content generally has a large effect on the grapes' value to wineries. For these reasons, we measured the weight of the berry yield and sampled sugar concentrations for inoculated and control vines in both years. In 1988, we found nodifferences in berry weight or in sugar concentration for the two treatments (table 1). In 1989, however, vines that had been inoculated with Willamette mites the previous year had higher berry sugar concentrations than the previous year's controls (fig. 5). Vines that had been "vaccinated" in 1989 also had higher berry sugar levels that year than did uninoculated vines (fig. 5). Berry weights were unaffected in 1989 (table 1).

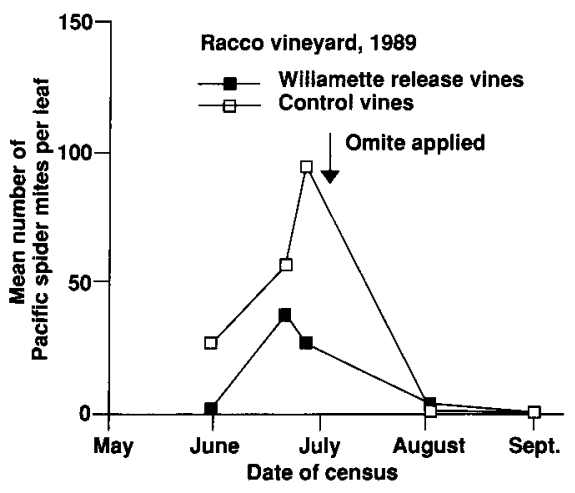

Fig. 4. Pacific spider mite populations on experimental Zinfandel vines throughout the 1989 growing season. Release vines $(n=15$ rows) received $549 \pm 136$ Willamette mites each on April 17, and control vines ( $n=15$ rows) received no Willamette mites. The 1989 experiment was in a different area of the vineyard than the 1988 experiment.

\begin{tabular}{|c|c|c|}
\hline \multirow[b]{2}{*}{ Plot and year } & \multicolumn{2}{|c|}{ Mean yield per vine ${ }^{\star}$} \\
\hline & $\begin{array}{l}\text { Willamette } \\
\text { release } \\
\text { vines }\end{array}$ & $\begin{array}{l}\text { Control } \\
\text { vines }\end{array}$ \\
\hline \multirow{4}{*}{$\begin{array}{l}1988 \text { plot, } 1988 \\
1988 \text { plot, } 1989 \\
1989 \text { plot, } 1989\end{array}$} & & ............ \\
\hline & 4.16 & \\
\hline & 5.31 & 6.01 \\
\hline & 10.57 & 8.90 \\
\hline
\end{tabular}

*Means were not statistically different between treatments in 1989 or 1990.

\section{Potential for success}

Vaccinating grapevines with Willamette mites will only make sense for a vineyard with a history of Pacific spider mite problems. Willamette mites have the potential to damage grapevines and reduce yields early in the season or under cool conditions. Populations of Willamette mites build up to economically damaging densities in the cooler, mesic grape growing regions of the Sierra foothills and coastal valleys. In these regions, growers must exercise greatcaution in releasing Willamette mites. In the Central Valley, Willamette mites normally are not a cause for economic concern, although there are rare exceptions.

In our experience, Zinfandel grape vaccinations have provided consistently good results. Results with Chardonnay vines are limited, but they too are encouraging. However, effects on Thompson Seedless vines are inconsistent both in small plot experiments and commercial trials conducted in Delano vineyards managed by Max Jehle. As such, we cannot recommend Willamette mite vaccination for Thompson Seedless vines.

\section{How it works}

Our greenhouse and field results indicate that Willamette mites can reduce Pacific

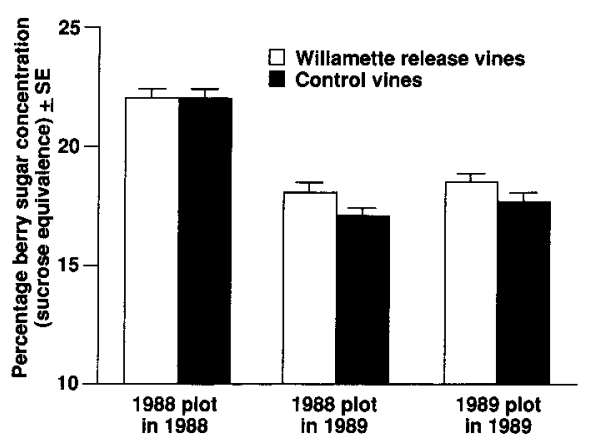

Fig. 5. Berry sugar concentrations for Zinfandel vines used in the 1988 and 1989 Willamette release experiments. For the 1988 study, we measured sugar concentrations both in 1988 and in 1989. spider mite populations through a number of mechanisms. Don Flaherty (Cooperative Extension Farm Advisor, Tulare County) has observed that populations of predatory mites (Metaseiulus occidentalis) increase on grapevines with early season populations of Willamette mites. Later in the season, when Pacific spider mites would otherwise begin to increase, this large predator population keeps the Pacific spider mites in check.

Recent experiments by Rachid Hanna (former Graduate Student, UC Davis) confirm this observation. A buildup of predators may have been responsible for the lack of resurgence in the Pacific spider mite population at our study site late in the 1989 season (fig. 4). During 1989, we observed many predaceous mites and thrips (six-spotted thrips, Scolothrips sexmaculatus) in the vineyard.

However, increases in predator populations cannot explain our greenhouse and small plot results (figs. 1 and 2). These experiments were conducted under conditions that wereessentially predator free. Similarly, never in our 1988 commercial vineyard experiment did we observe these predators until the very last sampling date. Predators were far too rare to have provided the control we observed. Although we do not fully understand what other mechanisms are at work in the grape agroecosystem, our preliminary results indicate that reduced plant suitability for Pacific mites is involved. In future research, we plan to get a better handle on how this vaccination process works.

\section{Conclusions}

Vaccinations have becomethe most effective tool for preventing diseases in vertebrates. In few cases do vaccinations cause hosts to be entirely free of disease organisms; rather, vaccinations increase the organism's ability to resist the disease, and so prevent the pathogen from increasing to levels at which disease symptoms are expressed. Entomologists have not explored similar techniques to reduce outbreaks of damaging insects and mites. Clearly, our experiments must be repeated before we can recommend that growers inoculate their vineyards with Willamette mites to prevent chronic problems with Pacific mites. Even at its best, this technique will not provide absolute control. However, the potential for using economically unimportant herbivores to control pest species may be substantial. As chemical insecticides are phased out, these novel techniques may provemore and more important.

Richard Karban is Associate Professor and Gregory English-Loeb is a Postdoctoral Researcher, Department of Entomology, UC Davis; and Paul Verdegaal is Farm Advisor, Cooperative Extension, San Joaquin County. The authors gratefully acknowledge the research support of the United States Department of Agriculture. 